DOI: $10.5800 / G T-2020-11-3-0492$

\title{
INHOMOGENEOUS STRUCTURE OF MAGNETIC LAYER OF THE KURIL ISLAND ARC
}

\author{
N.A. Palshin ${ }^{1}{ }^{\circledR}$, A.N. Ivanenko ${ }^{1}{ }^{1}$, D.A. Alekseev ${ }^{1,2,3}$
}

${ }^{1}$ Shirshov Institute of Oceanology, Russian Academy of Sciences, 36 Nahimovskiy Ave, Moscow 117997, Russia

${ }^{2}$ Moscow Institute of Physics and Technology, 9 Institutskiy Ln, Moscow Reg, Dolgoprudny 141701, Russia

${ }^{3}$ Schmidt Institute of Physics of the Earth, Russian Academy of Sciences, 10/1 Bolshaya Gruzinskaya St, Moscow 123242, Russia

ABSTRACT. An innovative technology of anomalous magnetic field inversion was applied to construct 2D models of the magnetic layer using three profiles crossing the southern, central and northern parts of the Kuril Island Arc. In the frontal area of the northern and southern parts, a zone of increased effective magnetization is clearly distinguished. In the central part of the island arc, increased magnetization is much less pronounced. Anomalous zones of positive effective magnetization have a deep part, the so-called "serpentinite wedge". The inhomogeneous lateral structure of the magnetic layer of the Kuril Island Arc suggests differences in the fluid regime and is reflected in the distribution of modern seismicity.

KEY WORDS: subduction zone; Kuril Island Arc; frontal area; magnetic layer; serpentinite; hydration; seismicity; anomalous magnetic field; inverse problem

FUNDING: The study was carried out in accordance with the state assignment of the RF Ministry of Science and Higher Education (№ 0149-2019-0006) with partial financial support from the RFBR (№ 18-05-00316).

\section{RESEARCH ARTICLE}

Correspondence: Nikolay A. Palshin, palshin@ocean.ru
Received: October 30, 2019

Revised: April 10, 2020

Accepted: April 14, 2020

FOR CITATION: Palshin N.A., Ivanenko A.N., Alekseev D.A., 2020. Inhomogeneous structure of magnetic layer of the Kuril Island arc. Geodynamics \& Tectonophysics 11 (3), 583-594. doi:10.5800/GT-2020-11-3-0492 


\title{
НЕОДНОРОДНОЕ СТРОЕНИЕ МАГНИТОАКТИВНОГО СЛОЯ КУРИЛЬСКОЙ ОСТРОВНОЙ ДУГИ
}

\author{
Н.А. Пальшин ${ }^{1}$, А.Н. Иваненко ${ }^{1}$, Д.А. Алексеев ${ }^{1,2,3}$ \\ ${ }^{1}$ Институт океанологии им. П.П. Ширшова РАН, 117997, Москва, Нахимовский пр-т, 36, Россия \\ ${ }^{2}$ Московский физико-технический институт (Национальный исследовательский университет), 141701, Дол- \\ гопрудный, Институтский пер., 9, Россия \\ ${ }^{3}$ Институт физики Земли им. О.Ю. Шмидта РАН, 123242, Москва, ул. Большая Грузинская, 10, стр. 1, Россия
}

\begin{abstract}
АНнОТАЦИЯ. На основе оригинальной технологии инверсии аномального магнитного поля построены двумерные модели магнитоактивного слоя по трем профилям, пересекающим Курильскую островную дугу в южной, центральной и северной части. В северной и южной части островной дуги во фронтальной зоне уверенно выделяется зона повышенной эффективной намагниченности. В центральной части дуги зона повышенной намагниченности выражена существенно слабее. Аномальные зоны положительной эффективной намагниченности имеют глубинную часть, которая соответствует так называемому «серпентинитовому валу». Выявленное неоднородное латеральное строение магнитоактивного слоя Курильской островной дуги свидетельствует о различиях во флюидном режиме и находит свое отражение в распределении современной сейсмичности.
\end{abstract}

КЛЮЧЕВЫЕ СЛОВА: зона субдукции; Курильская островная дуга; фронтальная зона; магнитоактивный слой; серпентинит; гидратация; сейсмичность; аномальное магнитное поле; обратная задача

ФИНАНСИРОВАНИЕ: Работа выполнена в соответствии с Государственным заданием Министерства науки и высшего образования РФ № 0149-2019-0006 при частичной поддержке РФФИ (проект №18-05-00316).

\section{1. ВВЕДЕНИЕ}

Геофизические исследования глубинного строения зон субдукции важны для понимания происходящих в них процессов и построения тектонических моделей оболочек Земли. Кроме того, именно в зонах субдукции располагаются гипоцентры большинства катастрофических цунамигенных землетрясений, поэтому изучение их строения имеет также прикладное значение (прогнозирование землетрясений и цунами). Пространственное распределение сейсмичности как вдоль, так и поперек простирания островных дуг характеризуется существенной неоднородностью: особенности распределения сейсмичности уже давно изучаются исследователями островных дуг северо-западной части Тихого океана [Fedotov, 1965, 1968; Sykes, 1971]. Одной из моделей, объясняющих механизм генерации сильнейших сейсмических событий и сегментированность Курильской островной дуги, является «клавишная» модель, нашедшая экспериментальное подтверждение по данным GPS-наблюдений последних лет (например [Lobkovsky, Baranov, 1984; Baranov et al., 2015; Lobkovsky etal., 2017]). Имеются убедительные свидетельства сложного геологического строения Курильской островной дуги, в центральной части которой существуют условия растяжения в направлении, параллельном ее простиранию [Taira, 2001; Kulinich et al., 2007, 2012, 2015; Baranov et al., 2016].

Ключевой проблемой для понимания сейсмичности островных дуг являются особенности их флюидного режима, которые находят свое отражение в геофизических полях [Palshin, Alekseev, 2017]. Геомагнитные исследования - один из наиболее эффективных «классических» методов исследований геологического строения и тектоники морского дна. Аномальное магнитное поле акваторий является одним из основных геофизических источников информации об их геологическом строении и тектонической эволюции земной коры [Purucker, Clark, 2011]. Важно отметить, что получаемые модели независимы от традиционно используемых сейсмологических, плотностных и геоэлектрических моделей, поскольку магнитные свойства горных пород определяются другими физическими принципами.

Задача данной работы - анализ аномалий геомагнитного поля вдоль трех характерных профилей, пересекающих Курильскую островную дугу, построение моделей магнитоактивного слоя и их интерпретация, направленная на понимание особенностей флюидного режима, глубинного строения, а также их связи с сейсмичностью.

\section{2. ГИДРАТАЦИЯ И ДЕГИДРАТАЦИЯ ПОРОД В ЗОНЕ СУБДУКЦИИ}

Океанская литосферная плита, погружающаяся в зонах субдукции, несет большое количество воды, содержащейся в ее верхних слоях: осадочном чехле и первых слоях океанской коры в виде поровых флюидов, а также в породах верхней мантии в виде серпентинитов (рис. 1). Следует отметить, что степень серпентинизации верхней мантии океанов увеличивается с возрастом [Rupke et al., 2004].

Серпентиниты образуются в рифтовых зонах и трансформных разломах, в которых могут существовать гидротермальные циркуляционные ячейки, обеспечивающие поступление поверхностных флюидов на большие 


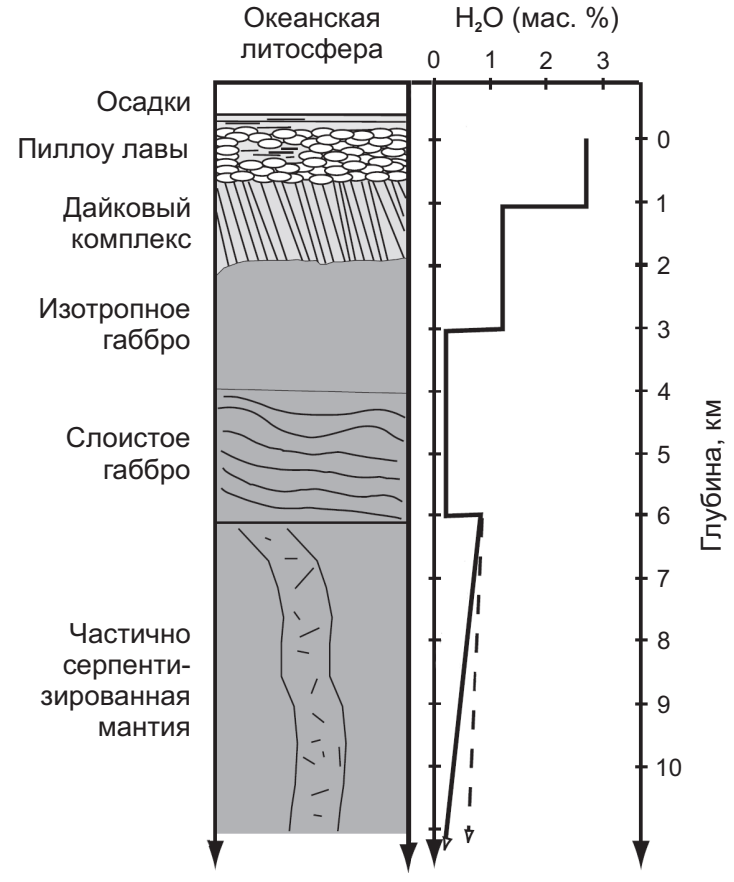

Рис. 1. Содержание воды в океанской литосфере.

Пунктиром показан вариант для старой литосферы. Модифицировано из [Rupke et al., 2004].

Fig.1. Water content in the oceanic lithosphere.

Dashed line - option for the ancient lithosphere. Modified from [Rupke et al., 2004].

глубины, где залегают ультраосновные магматические породы. В районе краевого вала (outer rise) глубоководных желобов может происходить дополнительная гидратация океанской плиты по системе сейсмически активных разломов [Kerrick, 2002; Carlson, Miller, 2003; Rupke et al., 2004]. Интенсивность этого процесса, возможно, связана с уровнем сейсмичности в области краевого вала. Например, в дальневосточных зонах субдукции сейсмичность в этой области высокая, что может свидетельствовать о существенном вкладе этого дополнительного источника гидратации.

Одной из наиболее известных и хорошо проработанных моделей процессов гидратации и дегидратации в зоне субдукции является модель, предложенная авторами статьи [Hyndman, Peacock, 2003], в которой подробно рассмотрено строение типичной зоны субдукции и процессы, происходящие в ней. Особое внимание уделено процессам образования и разрушения серпентинитов (рис. 2).

В глубоководном желобе и аккреционной призме происходит частичная дегидратация океанской коры: часть флюидов из верхних слоев океанской коры выдавливается в верхние слои и возвращается в атмосферу в виде летучих через сипы или через грязевой вулканизм (дегидратация и литификация илов). Далее часть флюидов захоранивается в зоне интенсивного складкообразования в процессе динамометаморфизма и продолжает движение с погружающейся плитой [Key et al., 2012].
На бо́льших глубинах, примерно в диапазоне от 20 до 40 км, захороненная в верхних слоях океанской литосферы вода участвует в образовании дополнительных объемов серпентинитов, которые могут слагать серпентинитовые валы на глубинах, соответствующих интервалу температур от 200 до $400{ }^{\circ} \mathrm{C}$ [Hyndman, Peacock, 2003; Popov et al., 2015]. Гидратация ультраосновных магматических пород и дегидратация серпентинитов играют ключевую роль в понимании механизмов транспортировки флюидов в зонах субдукции, физико-химических процессов, термодинамических условий, распределения сейсмичности, а также процессов образования очагов частичного плавления и островодужного вулканизма.

\section{3. АНОМАЛЬНОЕ МАГНИТНОЕ ПОЛЕ КАК ИНДИКАТОР ПРОЦЕССОВ СЕРПЕНТИНИЗАЦИИ}

Магнитное поле океана является одним из главных источников информации о геологическом строении океанской коры. При исследованиях аномального магнитного поля в океане установлена сложность его структуры, которую нельзя объяснить только базальтовыми источниками, без привлечения более глубоких слоев океанской коры и верхней мантии. Первичные ультрабазиты, слагающие нижние слои океанской коры, немагнитны или слабомагнитны, а образование магнетита и приобретение ими намагниченности связаны с процессами серпентинизации [Gorodnitskiy et al., 2017]. Именно серпентиниты обладают высокими значениями естественной остаточной намагниченности и фактора Кенигсбергера и поэтому вносят существенный вклад в аномальное магнитное поле. Магнитные свойства серпентинитов определяются ферримагнитными свойствами содержащегося в них магнетита, доля которого может достигать нескольких процентов, а

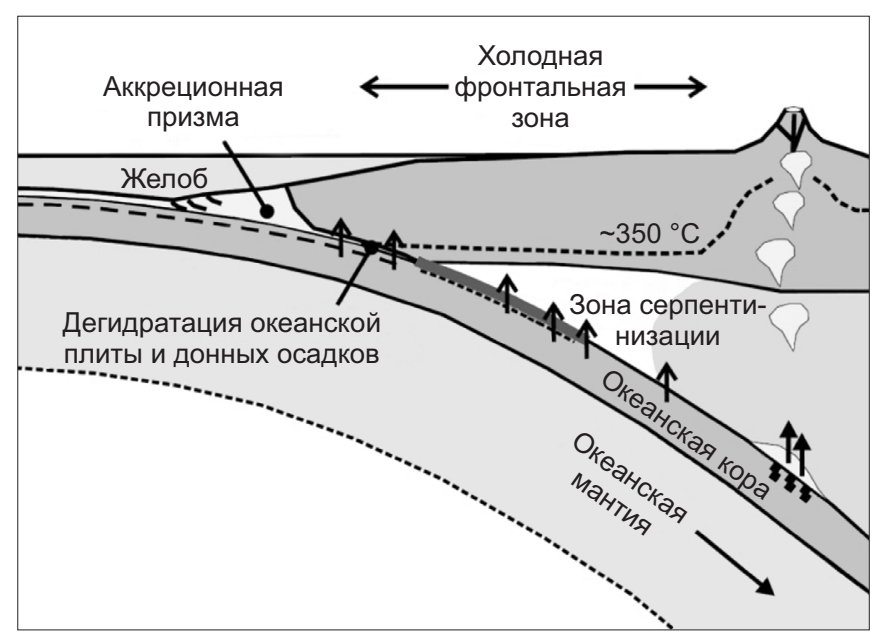

Рис. 2. Схематический разрез, иллюстрирующий флюидный режим зоны субдукции, включая процессы гидратации и дегидратации. Модифицировано из [Hyndman, Peacock, 2003].

Fig. 2. Schematic section illustrating the fluid regime of the subduction zone, including hydration and dehydration processes. Modified from [Hyndman, Peacock, 2003]. 
величина естественной остаточной намагниченности обусловлена концентрацией и степенью окисления ферримагнетиков и слабо зависит от первоначального химического состава ультрабазитов, и в частности от содержания в них железа (например [Popov et al., 2015]). Следовательно, изучение магнитных свойств серпентинитов позволяет получать информацию о процессах происхождения и геологической истории как самих серпентинитов, так и всей океанской коры в целом, а также выявлять связь процессов серпентинизации с тектонической эволюцией океанской литосферы.

Направление, величина и другие свойства намагниченности в серпентинитах связаны с геологическими условиями, в которых происходят процессы серпентинизации. Так, интенсивные вытянутые магнитные аномалии, выявленные во фронтальных зонах некоторых зон субдукции, вызываются серпентинитовыми валами, образующимися в результате гидратации ультрабазитов верхней мантии океанской водой, проникающей по системе трещин в пододвигаемой плите на ее изломе на критической глубине в процессе поддвига. Изучение этих аномалий позволяет получать информацию о процессах гидратации пород океанской коры в зонах субдукции [Maekawa et al., 2001; Blakely et al., 2005; Purucker, Clark, 2011].

\section{4. АНОМАЛИИ МАГНИТНОГО ПОЛЯ ВО ФРОНТАЛЬНОЙ ЗОНЕ КУРИЛЬСКОЙ ОСТРОВНОЙ ДУГИ}

Рассмотрим распределение сейсмичности и магнитных аномалий в районе Курильской островной дуги. В первом приближении можно выделить три области: южную, центральную и северную, в которых наблюдаются характерные особенности как в распределении сейсмичности, так и в аномальном магнитном поле (рис. 3,4 ).

Распределение сейсмичности вдоль Курильской островной дуги неоднородно (см. рис. 3). Южная зона характеризуется высокой сейсмичностью и типичным для большинства островных дуг распределением эпицентров и глубин гипоцентров. Особенностью центральной части Курильской дуги является большое количество неглубоких землетрясений в области краевого вала: ни в северной, ни в южной части дуги таких землетрясений практически нет. В северной части островной дуги сейсмичность существенно ниже: в области краевого вала и фронтальной области дуги землетрясения практически отсутствуют. Важно отметить, что в направлении с юго-запада на северо-восток угол погружения океанской плиты увеличивается от 30 до 40 и даже $45^{\circ}$ в области самой островной дуги, а в задуговой части эта разница становится еще более очевидной [Hayes, 2018].

Неоднородно также и аномальное магнитное поле, в котором, как и в распределении сейсмичности, можно выделить три области (рис. 4). Южная и северная части фронтальной зоны характеризуются обширными сложно построенными, но в целом положительными аномалиями магнитного поля, тогда как в центральной части, где предполагается растяжение, положительная аномалия магнитного поля выражена не так ярко.

Для понимания особенностей аномального магнитного поля и строения магнитоактивного слоя для трех выбранных профилей (рис. 3 и 4) с помощью усреднения значений аномального магнитного поля и батиметрии был вычислены средние значения глубины D и аномального магнитного поля $\Delta$ Та. Усреднение выполнялось для каждой точки профиля с радиусом 50 км. Начало координат для всех профилей было помещено в ось глубоководного желоба (рис. 5).

Особенности поведения аномального магнитного поля на каждом из профилей отражают региональное глубинное строение магнитоактивного слоя Курильской островной дуги. Для этих профилей была решена обратная задача и построены модели эффективной намагниченности.

\section{5. МЕТОДИКА ДВУМЕРНОЙ ИНВЕРСИИ АНОМАЛЬНОГО МАГНИТНОГО ПОЛЯ}

Для решения обратной задачи восстановления распределения эффективной намагниченности в земной коре по аномальному магнитному полю, измеренному на поверхности, была использована технология, основанная на предложенных нами ранее подходах [Gorodnitskiy et al., 2013; Dolgal' et al., 2017]. Она позволяет находить устойчивые контрастные решения с привлечением доступной априорной информации в рамках двумерного подхода и включает в себя итерационный процесс, при котором чередуются вычисления по выбранным алгоритмам, и принятие решений исследователем относительно применения той или иной технологии обработки и шагов инверсии.

На первом этапе, который включает определение области решения, задание начального приближения и дискретизацию модели, по комплексу магнитных и всех других доступных геолого-геофизических данных выделяется область пространства, внутри которой будет вычисляться распределение аномальной эффективной намагниченности, создающее наблюдаемые аномалии. Хорошие результаты на этом этапе дают методы особых точек, позволяющие определять положение верхних и нижних кромок аномальных тел, спектральные и корреляционные способы оценки интегральных параметров источников аномалий, методы разделения аномалий, решение прямых задач (case study) для исключения эффектов от известных источников, к примеру, немагнитной осадочной толщи. Поскольку эти методы работают как в пространственной, так и в спектральной области, используют различные трансформанты поля, взаимно контролирующие друг друга. Полученные таким образом усредненные оценки интегральных параметров являются наиболее обоснованными и объективными, что существенно снижает неоднозначность решения обратной задачи, поскольку оно стартует с реалистичного начального приближения и не приводит к получению неправдоподобных экзотических решений (артефактов). 


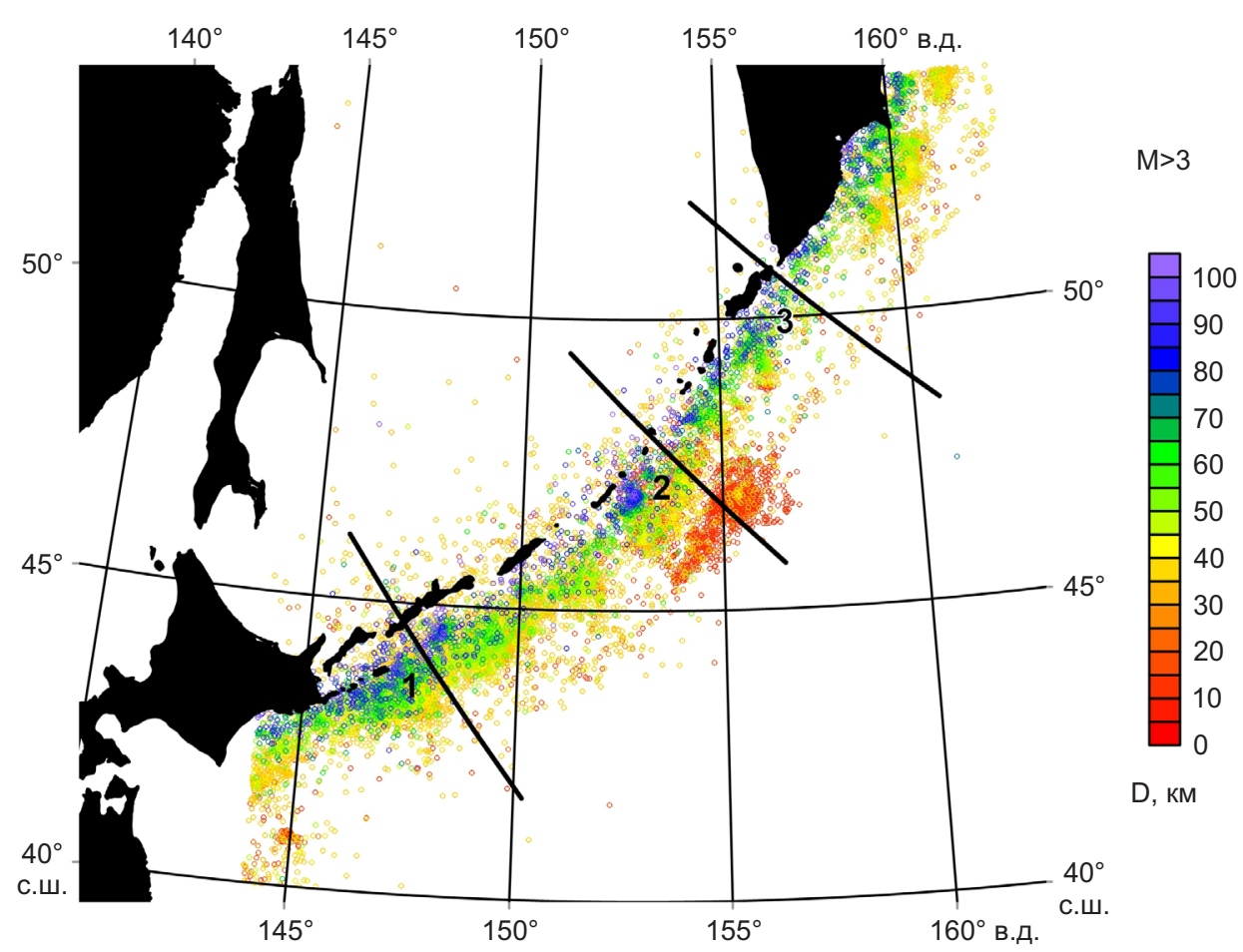

Рис. 3. Сейсмичность Курильской островной дуги.

Показано расположение эпицентров землетрясений с М>3 за интервал времени с 1964 по 2019 г. [Bulletin of the International Seismological Centre..., 2017]. Цветом показана глубина D до гипоцентров. 1 - южная часть, 2 - северная часть, 3 - центральная часть Курильской островной дуги. Положение расчетных профилей показано черными линиями.

Fig. 3. Seismicity of the Kuril Island Arc.

Locations of $M>3$ earthquake epicenters (1964 to 2019) from [Bulletin of the International Seismological Centre..., 2017]. Colours differ to show depths to hypocenters, D. Parts of the Kuril Island Arc: 1 - southern, 2 - northern, 3 - central. Black lines - profiles.

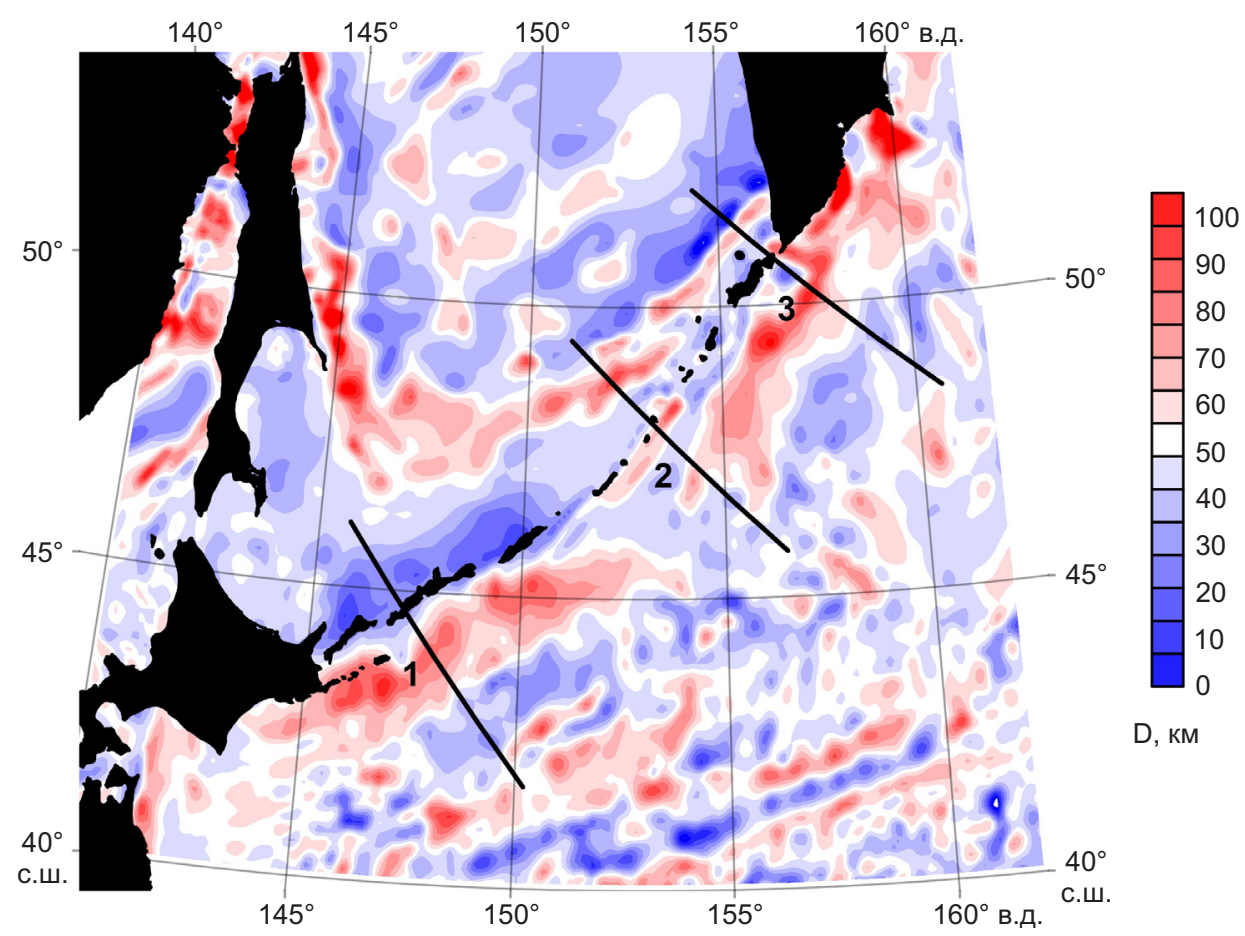

Рис. 4. Аномальное магнитное поле $\Delta$ Та [Meyer et al., 2017].

1 - южная часть, 2 - северная часть, 3 - центральная часть Курильской островной дуги. Положение расчетных профилей показано черными линиями.

Fig. 4. Anomalous magnetic field, $\Delta$ Ta [Meyer et al., 2017].

Parts of the Kuril Island Arc: 1 - southern, 2 - northern, 3 - central. Black lines - profiles. 
В данном исследовании область поиска эффективной намагниченности была ограничена рельефом дна и мощностью осадочного слоя для океанской и охотоморской части расчетных профилей. Рассчитанные методом особых точек положения верхних и нижних кромок магнитоактивных тел еще более сужают область решения обратной задачи, повышая его устойчивость.
Выбранная область в нижнем полупространстве разбивается на трапецеидальные (с вертикальными боковыми границами) элементарные тела. У рассматриваемых профилей их горизонтальный размер был фиксирован и составлял 5 км, а вертикальный зависел от количества горизонтальных слоев (18-21) и варьировался от 1.2 до 2.7 км; в результате общее количество элементарных тел составляло порядка 2500. Для каждого

(a)
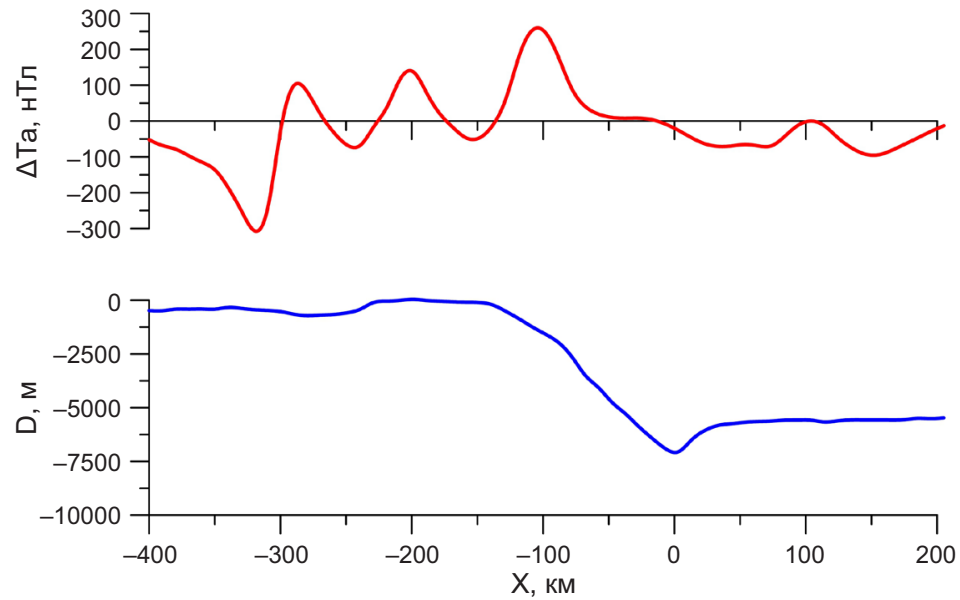

(б)
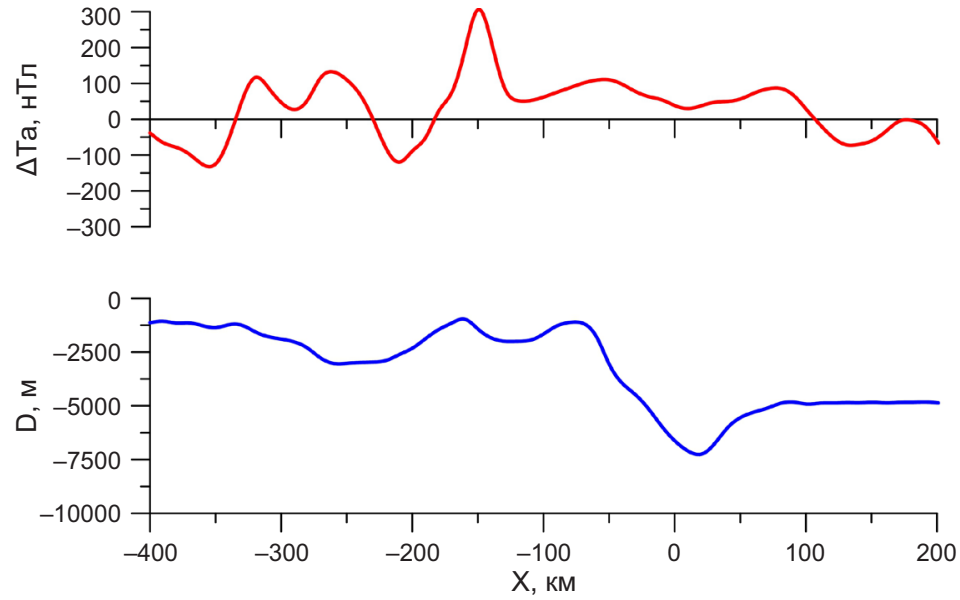

(8)
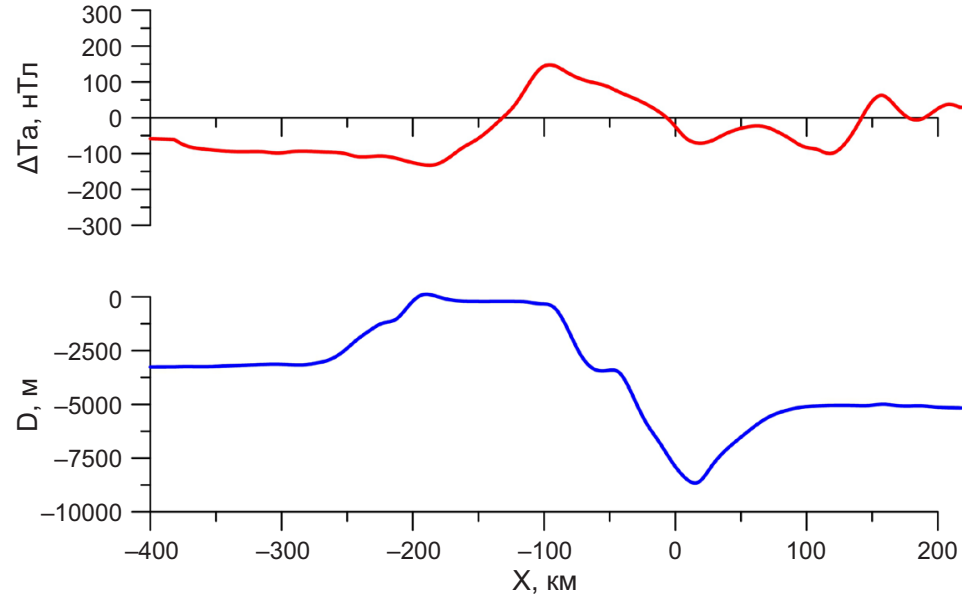

Рис. 5. Значения усредненных глубины D и аномального магнитного поля $\Delta$ Та вдоль трех выбранных профилей: 1 (a), 2 (б) и 3 (в). Расположение профилей см. на рис. 3 и 4.

Fig. 5. Average depth, D and anomalous magnetic field, $\Delta$ Ta for profiles 1 (a), 2 (б), and 3 ( 8 ). See Figs. 3 and 4 for the locations of profiles. 
элементарного тела решается прямая задача по множеству точек наблюдения. Слои такой сетки конформны верхней и нижней границе области поиска решений, что обеспечивает хорошее разрешение по вертикали. Разбиение на элементарные тела с постоянной намагниченностью приводит к дискретизации изначально непрерывного интегрального уравнения, описывающего связь источников аномалий и создаваемого ими поля. При этом задача сводится к поиску решения системы линейных уравнений большой размерности:

$$
A m=y,
$$

где $A$ - матрица решения прямой задачи, $m$ - искомое распределение намагниченности, $y$ - измеренное поле $\Delta \mathrm{Ta}$.

На втором этапе строится регуляризованное устойчивое решение, одновременно минимизирующее невязку между наблюденным и модельным полями, и стабилизатор-функционал, отражающий выбранные желательные свойства решения - его норму («псевдорешение»), гладкость («Оккам-инверсия»), энтропию и т.п. [Zhdanov, 2002]:

$$
\|A m-\lambda y\|+\|R(m)\| \rightarrow \min ,
$$

где $\lambda$ - параметр регуляризации, $R(m)$ - регуляризующий функционал.

Нами был реализован матричный подход к решению задачи регуляризации за счет псевдообращения расширенной матрицы, включающей в себя матрицу прямой задачи и матрицу, соответствующую стабилизатору (единичная для псевдорешения, матрица численного дифференцирования - для гладкого решения):

$$
\left(\frac{A}{\lambda R}\right) m=\left(\frac{y}{0}\right) .
$$

Поиск регуляризованных решений ведется с помощью SVD-разложения объединенной матрицы прямой задачи, расширенной блоком минимизации нормы решения и/или его гладкости (единичная матрица и/или матрица оператора численного дифференцирования по горизонтали и/или вертикали), соответствующих стабилизатору. SVD-способ, хотя и считается более затратным по вычислениям, является более точным и устойчивым по сравнению с другими численными методами обращения больших матриц, например методом сопряженных градиентов. Кроме того, он позволяет в явном виде контролировать невязку между измеренным и модельным полем, что является основой и смыслом метода регуляризации.

Третий этап сводится к анализу полученного регуляризованного (обычно - переглаженного) решения и сравнению его с имеющейся информацией о геологическом строении изучаемой области. На этом этапе проверяется адекватность полученных оценок физических свойств, эффективной намагниченности, в нашем случае - попадание их в априорно заданный интервал, выделяются и формализованно закрепляются основные границы геолого-тектонических тел и блоков.
Матричный подход очень удобен в смысле влияния на желательные свойства решений - за счет приписывания соответствующих весов соответствующим строкам расширенной матрицы можно усиливать или ослаблять их вклад в невязку общего решения. Таким же образом можно влиять на закрепление или ослабление контрастности сопряженных участков в распределении намагниченности - через усиление или ослабление весов в соответствующих строках подматрицы, соответствующей дискретной аппроксимации оператора дифференцирования решения по вертикали и/или горизонтали. Эта работа ведется с использованием интерактивного графического интерфейса. В итоге получается «грубая» геолого-геофизическая модель строения изучаемой области, отражающая ее основные, в первую очередь глубинные, особенности.

Четвертый этап заключается в построении детальной, контрастной модели с более высоким разрешением геологического строения изучаемой области путем итерационного уточнения решений методами локализации источников [Last, Kubik, 1983] и или минимизации области с высоким градиентом эффективной намагниченности [Portniaguine, Zhdanov, 2002]. Формально это сводится к добавлению к минимизируемой части (2) дополнительного члена - функционала, пенальтизирующего нежелательные свойства решения - его некомпактность или нечеткость границ, и приводит, по сути, к двухпараметрической регуляризации:

$$
\|A m-y\|+\lambda\|R(m)\|+\mu\|S(m)\| \rightarrow \min ,
$$

где $S(m)$ - штрафной функционал за нежелательные свойства решения.

Далее мы снова используем SVD-разложение матрицы из (3), но уже расширенной соответствующим блоком за счет дискретизации для $S(m)$. Минимизация теперь ведется на подмножестве решений, соответствующих заданной невязке (и $\lambda \leq \lambda_{0}$, ей соответствующей), обычно равной 1 \% от амплитуды аномального поля. В случае получения на выходе итерационного процесса неудовлетворительных (расходящихся по решению «рассыпающихся» или расходящихся по полю переглаженных) решений шаги 3 и 4 могут повторяться с измененными начальными условиями и параметрами, регулирующими сходимость процесса. Все три решения, рассмотренные дальше в статье, получены с использованием этого подхода.

\section{6. СТРОЕНИЕ МАГНИТОАКТИВНОГО СЛОЯ КУРИЛЬСКОЙ ОСТРОВНОЙ ДУГИ}

Построенные для трех профилей модели магнитоактивного слоя приведены на рис. 6, 7, 8. Первое, что обращает на себя внимание, - существенное различие моделей. Рассмотрим их более подробно.

Профиль 1. Модель магнитоактивного слоя для первого (южного) профиля характеризуется наличием ярко выраженной положительно намагниченной области (0.5-1.0 A/м) во фронтальной части дуги (см. рис. 6). Аномальная зона погружается в направлении 
на северо-запад от глубины, соответствующей верхней кромке в районе желоба (10 км), до 40 км в зоне субдукции. Ее ширина составляет около 150 км. Важно отметить, что граница океанской и континентальной плит, в соответствии с моделью Slab2 [Hayes, 2018], пересекает зону аномальной намагниченности таким образом, что одна часть зоны аномальной намагниченности располагается в пределах континентального клина, а другая - в пределах погружающейся океанской плиты. Большинство гипоцентров землетрясений расположено на нижней границе зоны повышенной намагниченности или глубже ее. Большая часть многочисленных гипоцентров землетрясений концентрируется в океанской плите во фронтальной зоне островной дуги (-50...-130 км). Также выделяется небольшая зона отрицательной намагниченности в области краевого вала (50-100 км) на глубине менее 20 км.

Обращает на себя внимание погружение нижней кромки магнитоактивного слоя в зоне субдукции до 55 км. Максимальная концентрация гипоцентров землетрясений находится именно в этой области погружения нижней кромки магнитоактивного слоя. На северо-западной окраине Тихоокеанской плиты нижняя кромка залегает на глубине около 25 км, а задуговая часть под Охотским морем - на глубине менее 20 км.

Профиль 2. В модели магнитоактивного слоя для второго (центрального) профиля, в отличие от первого, нет ярко выраженной аномальной области с положительной намагниченностью (см. рис. 7). Вместо нее выделяются две небольшие области, одна во фронтальной области $(-25 \ldots-100$ км) в интервале глубин от 10 до 20 км и вторая, вытянутая в вертикальном направлении под островной грядой $(-150 \ldots-180$ км), в интервале глубин от 10 до 30 км. Граница плит пересекает первую выделенную область, тогда как вторая область полностью лежит в пределах континентального клина. На профиле имеются три зоны с отрицательной намагниченностью: одна обширная на юго-восточном краю модели с глубиной залегания от 15 до 30 км и шириной 100 км в океанской части профиля, а также две относительно небольших по размеру области в задуговой части профиля.

Практически все гипоцентры землетрясений также концентрируются в океанской плите во фронтальной области островной дуги глубже первой выделенной области с положительной намагниченностью. Обращает на себя внимание наличие большого числа гипоцентров, включая и сильные землетрясения, в области краевого вала (0-50 км). Эта особенность сейсмичности данной части Курильской дуги так же хорошо видна на рис. 3, где представлено пространственное распределение эпицентров землетрясений.

Глубина до нижней кромки магнитоактивного слоя лежит в интервале от 35 до 45 км, слабо изменяясь вдоль профиля.

Профиль 3. На северном профиле, так же как и на южном, выделена область положительных значений эффективной намагниченности (0.5-1.0 А/м) во фронтальной области (рис. 8). Эта область шириной почти в 100 км, как и аналогичная область, выделенная на первом профиле, располагается в пределах как океанской, так и континентальной плиты на глубинах от 15 до 50 км.

Сейсмичность в северной части Курильской островной дуги существенно ниже, чем в южной и центральной части (см. рис. 3 и 8). Практически все гипоцентры землетрясений расположены в океанской плите. Большинство из них находится в нижней части области положительной намагниченности или глубже ее.

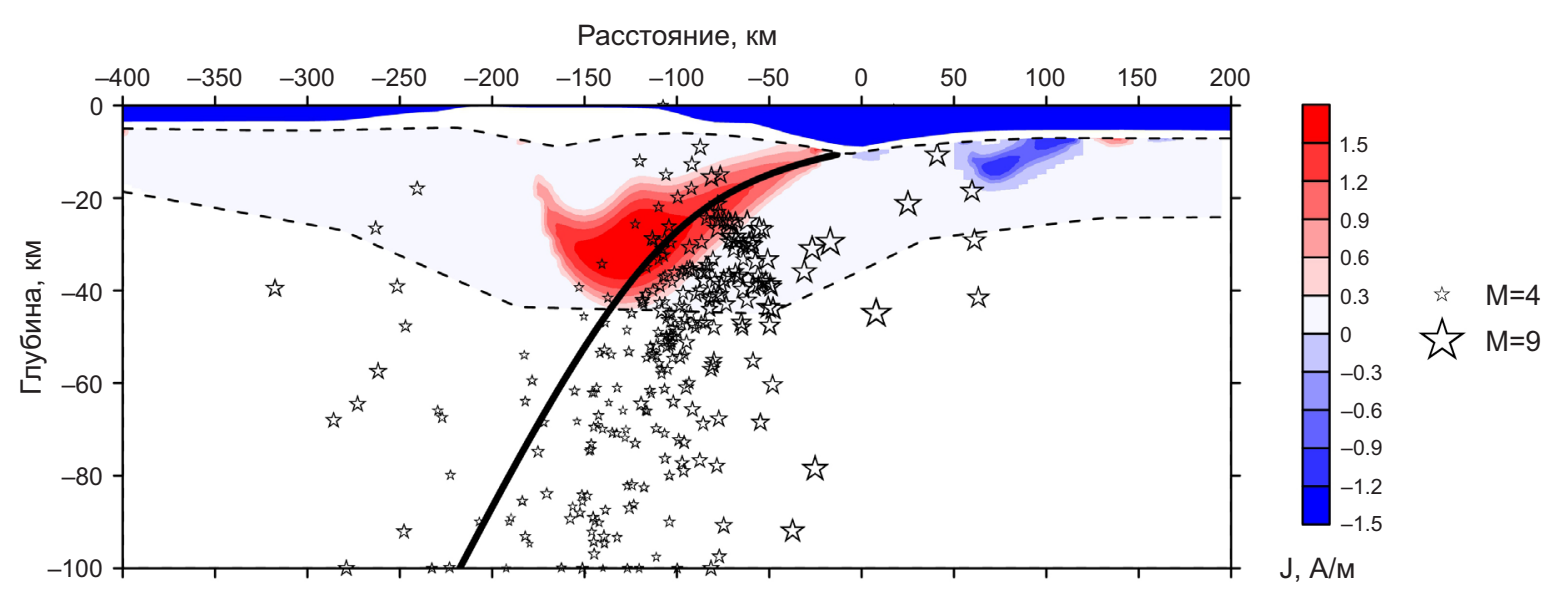

Рис. 6. Модель магнитоактивного слоя Ј для профиля 1.

Цветом показаны значения эффективной намагниченности. Пунктирные линии соответствуют верхней и нижней кромкам магнитоактивного слоя, ограничивающим область поиска решения. Толстой линей показано положение кровли Тихоокеанской плиты [Hayes, 2018]. Гипоцентры землетрясений (смещены на профиль из полосы шириной в 50 км) показаны звездочками, размер которых характеризует магнитуду [Bulletin of the International Seismological Centre..., 2017].

Fig. 6. Magnetic layer model of profile 1.

Colours show effective magnetization J. Dashed lines - upper and lower boundaries of the magnetic layer, which specify the problem solving area. Thick line - top of the Pacific plate [Hayes, 2018]. Stars - earthquake hypocenters (shifted to the profile from a 50-km wide strip); the stars differ is size to show magnitude M [Bulletin of the International Seismological Centre..., 2017]. 


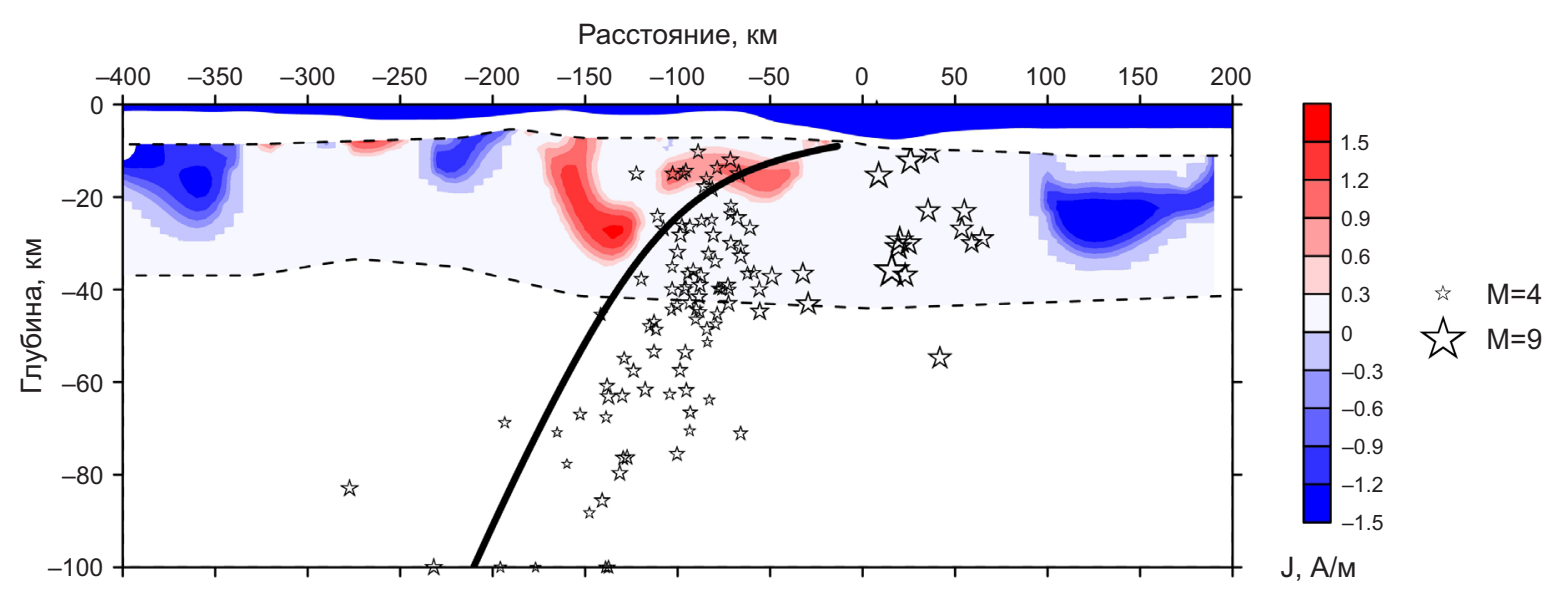

Рис. 7. Модель магнитоактивного слоя Ј для профиля 2. Обозначения см. на рис. 6.

Fig. 7. Magnetic layer model of profile 2. See Fig. 6 for legend.

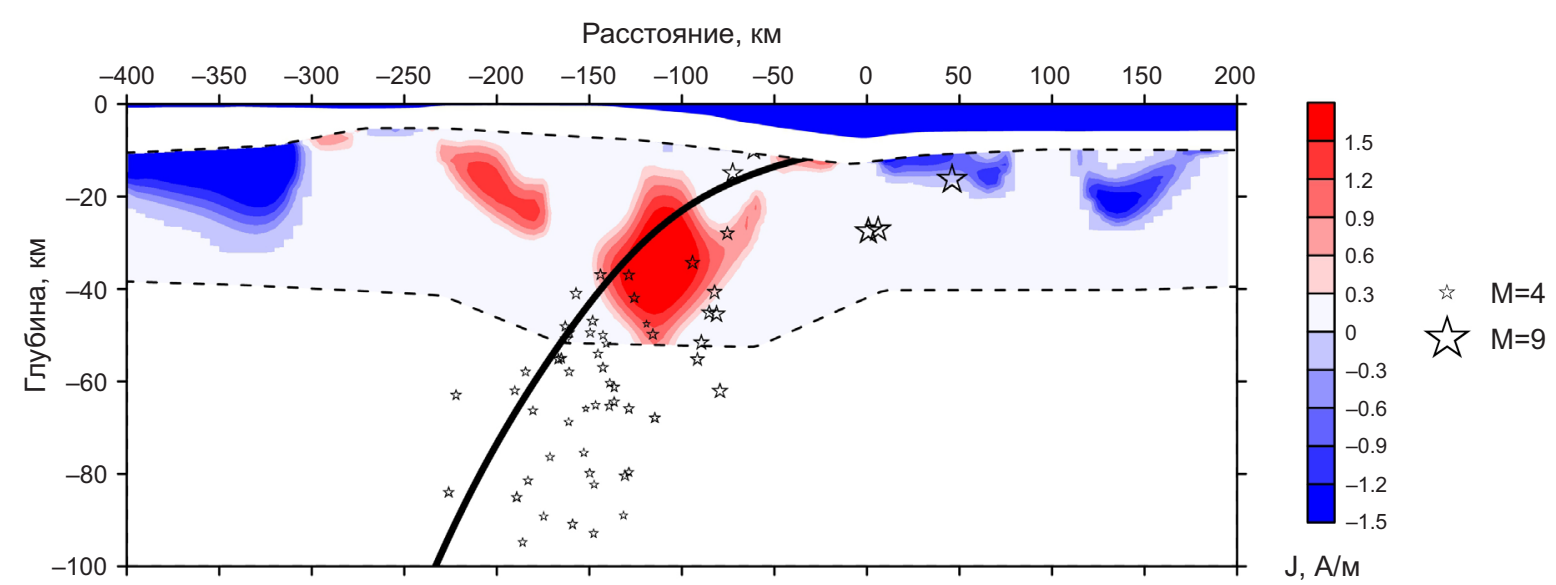

Рис. 8. Модель магнитоактивного слоя Ј для профиля 3. Обозначения см. на рис. 6.

Fig. 8. Magnetic layer model of profile 3. See Fig. 6 for legend.

Кроме аномальной области во фронтальной зоне выделена еще одна зона положительной намагниченности за островной дугой $(-180 \ldots-230$ км) в интервале глубин от 10 до 25 км шириной 50 км. Две относительно небольшие области отрицательной намагниченности обнаружены в океанской части профиля $(0-70$ км и 90-180 км) на небольших глубинах. Еще одна отрицательная аномалия намагниченности шириной более 100 км выделяется в задуговой части профиля. Она расположена на самом конце профиля, и ее параметры могут оцениваться недостаточно точно из-за краевых эффектов.

Глубина до нижней кромки магнитоактивного слоя в задуговой и океанской части составляет около 40 км, а в зоне субдукции достигает, как и на первом профиле, 55 км.

\section{7. ДискУссия и выводы}

Использование пространственного усреднения аномального магнитного поля и ограничение области поиска решения обратной задачи с помощью независимого определения глубины до верхних и нижних кромок магнитоактивного слоя позволили в значительной мере исключить из входных данных интенсивные приповерхностные локальные аномалии магнитного поля, вызываемые вулканическими постройками и серпентинитовыми диапирами, и сфокусировать инверсию магнитных данных на региональных глубинных объектах.

Важным результатом стало выявленное различие строения магнитоактивного слоя в южной, центральной и северной части Курильской островной дуги (см. рис. $6,7,8)$. Различаются эти три части островной гряды также и по современной сейсмичности (см. рис. 3). Скорость погружения океанской плиты в пределах Курильской островной дуги увеличивается примерно от 9 см/год в северной части до 10 см/год - в южной [Taira, 2001], также имеет место небольшое увеличение угла погружения океанской плиты с юга на север [Hayes, 2018]. По всей видимости, наблюдаемые отличия строения магнитоактивного слоя связаны в основном с различиями во флюидном режиме, которые, в свою очередь, определяются особенностями геологического строения континентального клина и погружающейся океанской плиты. В частности, именно этими 
причинами рядом автором объясняются особенности флюидного режима и сейсмичности зоны субдукции в Южной Америке (например [Araya Vargas, 2016; Kapinos et al., 2016]).

На всех профилях, в особенности на северном и южном, выделены обширные глубинные (15-50 км) области аномальной положительной эффективной намагниченности (0.5-1.0 А/м) во фронтальной зоне, которые идентичны известным в Алеутской и Японской островных дугах серпентинитовым валам [Maekawa et al., 2001; Blakely et al., 2005; Purucker, Clark, 2011], что позволяет с большой долей уверенности утверждать, что аномальная положительная намагниченность во фронтальной зоне Курильской островной дуги связана с серпентинитами. Таким образом, по магнитным данным, так называемый серпентинитовый вал хорошо выделяется в северной и южных части дуги, тогда как в центральной ее части он выражен слабее. Эта особенность центральной части Курильской островной дуги может быть связана с существованием зоны растяжения [Taira, 2001; Kulinich et al., 2007, 2012, 2015; Baranov et al., 2016] и, как следствие, повышенной раздробленности и проницаемости верхних слоев литосферы. В силу этого часть флюидов возвращается через разломные зоны в океан, а объем флюидов, поступающих с субдуцирующей плитой на большие глубины, снижается, что, в свою очередь, приводит к уменьшению количества образующихся серпентинитов.

Многочисленные концептуальные модели образования серпентинитов в зонах субдукции, как правило, предполагают, что серпентинитовый вал располагается в континентальном клине [Hyndman, Peacock, 2003; Blakely et al., 2005]. Имеются и модели, в которых образование серпентинитов предполагается также в океанской плите (например [Kogiso et al., 2009; Blanco-Quintero et al., 2011]). Характерной особенностью полученных нами моделей является то, что серпентинитовый вал располагается как выше, так и ниже границы раздела плит, то есть как в континентальном клине, так и в субдуцирующей океанской плите. Это факт находится в некотором противоречии с рядом классических моделей. Однако очевидно, что верхние слои океанской плиты (океанская кора) изначально содержат некоторое количество воды и ультраосновных магматических пород, которые при соответствующих термодинамических условиях могут быть источником образования серпентинитов. Поскольку для этого процесса тремя ключевыми факторами являются термодинамические условия, наличие ультрабазитов и воды, образование серпентинитов в верхней части океанской плиты представляется вполне естественным, что подтверждается построенными нами моделями.

Обращает на себя внимание характерное расположение гипоцентров землетрясений во фронтальной области дуги относительно серпентинитового вала: большая часть гипоцентров расположена в нижней части серпентинитового вала или, главным образом, глубже его (см. рис. 6, 7, 8). Влияние серпентинитов на сейсмичность и взаимосвязь процессов дегидратации серпентинитов и реологических свойств горных пород известно уже давно (например [Raleigh, Paterson, 1965]). Очевидно, что понимание особенностей строения серпентинитового вала может помочь в понимании закономерностей среднеглубинной сейсмичности [Gasc et al., 2017], однако для это требуются дополнительные исследования.

Существенно различаются также и глубины до нижней кромки магнитоактивного слоя, причем они различаются как вдоль профилей, так и между ними. Максимальная глубина до источников магнитных аномалий обычно считается эквивалентом глубины до изотермы Кюри (например [Li et al., 2017]), однако эта глубина также может быть и петрологической границей [Rajaram, 2007]. Во фронтальных областях островных дуг, в том числе и Курильской островной дуги, основным источником аномальной намагниченности является магнитит, содержащийся в серпентинитах. Процесс метаморфизации ультраосновных пород контролируется, в том числе, и температурным режимом в зоне субдукции. Таким образом, можно предположить, что в нашем случае глубина до нижней кромки магнитоактивного слоя, если и не эквивалентна глубине до изотермы Кюри, то хотя бы качественно отражает различия в температурном режиме.

Особый интерес представляет погружение нижней границы магнитоактивного слоя на южном и северном профилях до глубины 55 км вдоль границы плит (см. рис. 6 и 8), что подтверждает предполагаемое по комплексу геофизических данных погружение изотерм в зоне субдукции, а также существование «холодного» континентального мантийного клина во фронтальных областях зон субдукции [Abers et al., 2017]. Глубина в 55 км может соответствовать как изотерме Кюри для магнетита (примерно $580{ }^{\circ} \mathrm{C}$ ), так и глубине, на которой заканчивается зона, в которой могут протекать процессы метаморфизма ультраосновных пород. Тем не менее можно с уверенностью предположить, что глубинные температуры в зоне субдукции существенно ниже, чем в коре задугового бассейна в Охотском море и в океанской плите в области передового вала.

Латеральные неоднородности строения магнитоактивного слоя Курильской островной дуги обусловлены особенностями геологического строения и эволюции континентальной окраины (окраинной части Амурской плиты) и погружающейся под нее Тихоокеанской плиты.

\section{8. БЛАГОДАРНОСТИ}

Работа выполнена в соответствии с Государственным заданием Министерства науки и высшего образования РФ № 0149-2019-0006 при частичной поддержке РФФИ (№18-05-00316).

\section{9. ЛИТЕРАТУРА / REFERENCES}

Abers G.A., Van Keken P.E., Hacker B.R., 2017. The Cold and Relatively Dry Nature of Mantle Forearcs in Subduction 
Zones. Nature Geoscience 10, 333-337. http://doi.org//10. 1038/NGE02922.

Araya Vargas J.A., 2016. Large-Scale Distribution of Fluids in the Subduction Zone of Northern Chile - Constraints from Magnetotelluric Monitoring. PhD Thesis (Dr. Rer. Nat.). Berlin, 189 p. http://dx.doi.org/10.17169/refubium-6133.

Baranov B.V., Ivashchenko A.I., Dozorova K.A., 2015. The Great 2006 and 2007 Kuril Earthquakes, Forearc Segmentation and Seismic Activity of the Central Kuril Island Region. Pure and Applied Geophysics 172, 3509-3535. http:// doi.org//10.1007/s00024-015-1120-z.

Baranov B.V., Lobkovsky L.I., Dozorova K.A., 2016. Extension in the Frontal Part of the Central Kuril and Migration of the Trough. Reports of the Academy of Sciences 469 (3), 347-350 (in Russian) [Баранов Б.В., Лобковский Л.И., Дозорова К.А. Растяжение во фронтальной части Центральных Курил и миграция желоба // Доклады Академии наук. 2016. Т. 469. № 3. С. 347-350]. https://doi.org/ 10.7868/S0869565216210180.

Blakely R., Brocher T., Wells R., 2005. Subduction-Zone Magnetic Anomalies and Implications for Hydrated Forearc Mantle. Geology 33 (6), 445-448. https://doi.org/10.1130/ G21447.1.

Blanco-Quintero I.F., Proenza J.A., García-Casco A., Tauler E., Galí S., 2011. Serpentinites and Serpentinites within a Fossil Subduction Channel: La Corea Mélange, Eastern Cuba. Geologica Acta 9 (3-4), 389-405. http://doi.org// $10.1344 / 105.000001662$.

Bulletin of the International Seismological Centre Catalog Search, 2017. Available from: http://www.isc.ac.uk.

Carlson R.L., Miller D.J., 2003. Mantle Wedge Water Contents Estimated from Seismic Velocities in Partially Serpentinized Peridotites. Geophysical Research Letters 30 (5), 1250. http://doi.org//10.1029/2002GL016600.

Dolgal' A.S., Ivanenko A.N., Novikova P.N., Rashidov V.A., 2017. Serpentinites and Serpentinites within a Fossil Subduction Application of Modern Interpretive Geomagnetic Technologies for Studying Set Guyot (Markus-Necker mountains, Pacific Ocean). Geoinformatics 4, 38-47 (in Russian) [Долгаль А.С., Иваненко А.Н., Новикова П.Н., Рашидов В.А. Применение современных интерпретационных геомагнитных технологий для изучения гайота Сет (горы Маркус-Неккер, Тихий океан) // Геоинформатика. 2017. № 4. C. 38-47].

Fedotov S.A., 1965. Regularities in the Distribution of Strong Earthquakes in Kamchatka, the Kuril Islands and Northeastern Japan. Proceedings of the Institute of the Physics of the Earth of the USSR Academy of Science. Iss. 36. Nauka, Moscow, 66-93 (in Russian) [Федотов C.A. 0 закономерностях распределения сильных землетрясений Камчатки, Курильских островов и Северо-Восточной Японии // Труды Института физики Земли АН СССР. 1965. № 36. М.: Наука, 1965. С. 66-93].

Fedotov S.A., 1968. On the Seismic Cycle, the Possibility of Quantitative Seismic Zoning and Long-Term Seismicity Forecasting. In: Seismic Zoning of the USSR. Nauka, Moscow, p. 121-150 (in Russian) [Федотов C.A. O сейсмическом цикле, возможности количественного сейсмического районирования и долгосрочном сейсмическом прогнозе // Сейсмическое районирование СССР. М.: Наука, 1968. C. 121-150].

Gasc J., Hilairetb N., Ferrand Yu.T., Schubnel A., Wang, Y., 2017. Faulting of Natural Serpentinite: Implications for Intermediate-Depth Seismicity. Earth Planetary Science Letters 474, 138-147. https://doi.org/10.1016/j.epsl.2017. 06.016 .

Gorodnitskiy A.M., Brusilovskiy Yu.V., Ivanenko A.N., Filin A.M., Shishkina N.A., 2013. New Methods for Processing and Interpreting Marine Magnetic Anomalies: Application to Structure, Oil and Gas Exploration, Kuril Forearc, Barents and Caspian Seas. Geoscience Frontiers 4 (1), 73-85. https:// doi.org/10.1016/j.gsf.2012.06.002.

Gorodnitskiy A.M., Brusilovsky Yu.V., Ivanenko Yu.V., Popov K.V., Shishkina N.A., 2017. Nature of Magnetic Anomalies in Subduction Zones. Physics of the Earth 5, 185-192 (in Russian) [Городницкий А.М., Брусиловский Ю.В., Иваненко Ю.В., Попов К.В., Шишкина Н.А. Природа магнитных аномалий в зонах субдукции // Физика Земли. 2017. № 5. C. 185-192]. https://doi.org/10.7868/S0002333717 050052.

Hayes G., 2018. Slab2 - A Comprehensive Subduction Zone Geometry Model: U.S. Geological Survey Data Release. https://doi.org/10.5066/F7PV6JNV.

Hyndman R.D., Peacock S.M., 2003. Serpentinization of the Forearc Mantle. Earth and Planetary Science Letters 212 (3-4), 417-432. http://doi.org/10.1016/S0012-821X (03)00263-2.

Kapinos G., Montahaei M., Meqbel N., Brasse H., 2016. Three-Dimensional Electrical Resistivity Image of the SouthCentral Chilean Subduction Zone. Tectonophysics 666, 7689. http://doi.org/10.1016/j.tecto.2015.10.016.

Kerrick D., 2002. Serpentinite Seduction. Science 298 (5597), 1344-1345. http://doi.org/10.1126/science.298. 5597.1344.

Key K., Constable S., Matsuno T., Evans R.L., Myer D., 2012. Electromagnetic Detection of Plate Hydration Due to Bending Faults at the Middle America Trench. Earth and Planetary Science Letters 351-352, 45-53. http://doi.org/ 10.1016/j.epsl.2012.07.020.

Kogiso T., Omori S., Maruyama S., 2009. Magma Genesis beneath Northeast Japan Arc: A New Perspective on Subduction Zone Magmatism. Gondwana Research 16 (3-4), 446-457. http://doi.org/10.1016/j.gr.2009.05.006.

Kulinich R.G., Karp B.Ya., Baranov B.V., Lelikov E.P., Karnaukh V.N., Valitov M.G., Nikolaev S.M., Kolpashchikova T.N., Tsoi I.B., 2007. On the Structural and Geological Characteristics of the "Seismic Gap" in the Central Part of the Kuril Island Ridge. Pacific Geology 26 (1), 5-19 (in Russian) [Kyлинич Р.Г., Карп Б.Я., Баранов Б.В., Леликов Е.П., Карнаух В.Н., Валитов М.Г., Николаев С.М., Колпащикова Т.Н., Цой И.Б. О структурно-геологической характеристике «сейсмической бреши» в центральной части Курильской островной гряды // Тихоокеанская геология. 2007. T. 26. № 1. C. 5-19].

Kulinich R.G., Valitov M.G., Proshkina Z.N., 2012. Geophysical Fields, Block Structure and Seismic Activity of the 
Central Kuriles. Pacific Geology 31 (6), 35-43 (in Russian) [Кулинич Р.Г., Валитов М.Г., Прошкина З.Н. Геофизические поля, блоковая структура и сейсмическая активность Центральных Курил // Тихоокеанская геология. 2012. T. 31. № 6. C. 35-43].

Kulinich R.G., Valitov M.G., Proshkina Z.N., 2015. Comparative Analysis of Seismic and Density Models of the Crust in the Central Kuriles. Pacific Geology 34 (6), 45-56 (in Russian) [Кулинич Р.Г., Валитов М.Г., Прошкина 3.Н. Сравнительный анализ сейсмических и плотностных моделей земной коры Центральных Курил // Тихоокеанская геология. 2015. Т. 34. № 6. С. 45-56].

Last B.J., Kubik K., 1983. Compact Gravity Inversion. Geophysics 48, 713-72, https://doi.org/10.1190/1.1441501.

Li C.-F, Lu Y., Wang J., 2017. A Global Reference Model of Curie-Point Depths Based on EMAG2. Scientific Reports 7, 45129. http://doi.org/10.1038/srep45129.

Lobkovsky L.I., Baranov B.V., 1984. Keyboard Model of Strong Earthquakes on Island Arcs and Active Continental Margins. Reports of the USSR Academy of Sciences 275 (4), 843-847 (in Russian) [Лобковский Л.И., Баранов Б.В. Клавишная модель сильных землетрясений в островных дугах и активных континентальных окраинах // Доклады АН СССР. 1984. Т. 275. № 4. С. 843-847].

Lobkovsky L.I., Vladimirova I.S., Gabsatarov Yu.V., Garagash I.A., Baranov B.V., Steblov G.M., 2017. Postseismic Movements after the 2006-2007 Simushir Earthquakes at Various Stages of the Seismic Cycle. Reports of the Academy of Sciences 473 (3), 359-364 (in Russian) [Лобковский Л.И., Владимирова И.С., Габсатаров Ю.В., Гарагаш И.А., Баранов Б.В., Стеблов Г.М. Постсейсмические движения после симуширских землетрясений 2006-2007 гг. на различных стадиях сейсмического цикла // Доклады Академии наук, 2017. Т. 473. № 3. С. 359-364]. http://doi. org/10.7868/S0869565217090225.

Maekawa H., Yamanoto K., Teruaki I., Ueno T., Osada Y., 2001. Serpentinite Sea Mounts and Hydrated Mantle Wedge in the Izu-Bonin and Mariana Forearc Regions. Bulletin of Earthquake Research Institute 76, 355-366.

Meyer B., Saltus R., Chulliat A., 2017. EMAG2: Earth Magnetic Anomaly Grid (2-Arc-Minute Resolution). Version 3. National Centers for Environmental Information, NOAA. http://doi.org/10.7289/V5H70CVX.
Palshin N.A., Alekseev D.A., 2017. Features of Deep Electrical Conductivity in the Transition Zone from the Pacific Ocean to Eurasia. Physics of the Earth 3, 107-123 (in Russian) [Пальшин Н.А., Алексеев Д.А. Особенности глубинной электропроводности в зоне перехода от Тихого океана к Евразии // Физика Земли. 2017. № 3. С. 107-123]. https://doi.org/10.7868/S0002333717020107.

Popov K.V., Bazylev B.A., Shcherbakov V.P., Tsel'movich V.A., Kononkova N.N., 2015. Thermomagnetic Analysis of Ultramafic Rocks: A Case Study of Dunite from the Pekul'ney Complex, Chukotka, NE Russia. Russian Journal of Earth Sciences 15, ES1003. http://doi.org/10.2205/2015ES000547.

Portniaguine O., Zhdanov M.S., 2002. 3-D Magnetic Inversion with Data Compression and Image Focusing. Geophysics 67 (5), 1532-1541. http://doi.org/10.1190/1.15 12749.

Purucker M.E., Clark D.A., 2011. Mapping and Interpretation of the Lithospheric Magnetic Field. In: M. Mandea, M. Korte (Eds), Geomagnetic Observations and Models. P. 311-337. https://doi.org/10.1007/978-90-481-9858-0_13.

Rajaram M., 2007. Depth to Curie Temperature. In: D. Gubbins, E. Herrero-Bervera (Eds), Encyclopedia of Geomagnetism and Paleomagnetism. P. 157-159. http://doi.org/ 10.1007/978-1-4020-4423-6.

Raleigh C.B., Paterson M.S., 1965. Experimental Deformation of Serpentinite and Its Tectonic Implications. Journal of Geophysical Research 70 (16), 3965-3985. http://doi. org/10.1029/JZ070i016p03965.

Rupke L.H., Morgan J.P., Hort M., Connolly J.A.D., 2004. Serpentine and the Subduction Zone Water Cycle. Earth and Planetary Science Letters 223 (1-2), 17-34. http://doi.org/ 10.1016/j.epsl.2004.04.018.

Sykes L., 1971. Aftershock Zones of Great Earthquakes, Seismicity Gaps and Earthquake Prediction for Alaska and the Aleutians. Journal of Geophysical Research 76 (32), 8021-8041. http://doi.org/10.1029/JB076i032p08021.

Taira A., 2001. Tectonic Evolution of the Japanese Island Acr System. Annual Review of Earth Planetary Science 29, 109-134. https://doi.org/10.1146/annurev.earth. 29.1.109.

Zhdanov M.S., 2002. Geophysical Inverse Theory and Regularization Problems. Methods on Geochemistry and Geophysics. Vol. 36. Elsevier Science, Amsterdam, 633 p. 